\title{
Effects of Fluorides in the Flux Cored Wire on the Oxygen Content of Weld Metal
}

\author{
Joo-hyeon Cha $\circledast^{*}$ and Kook-soo Bang $\oplus^{*}$ \\ *Department of Materials System Engineering, Pukyong National University, Busan, Korea \\ 플럭스 코어드 와이어의 불화물 종류에 따른 용접금속 산소량의 변화

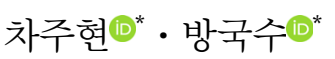 \\ "부경대학교 신소재시스템공학과
}

KEY WORDS: Flux cored wire 플럭스 코어드 와이어, Fluoride 불화물, Weld metal 용접금속, Oxygen content 산소량

\begin{abstract}
Various fluorides, i.e., $\mathrm{CaF}_{2}, \mathrm{Na}_{3} \mathrm{AlF}_{6}, \mathrm{~K}_{2} \mathrm{SiF}_{6}, \mathrm{MnF}_{3}, \mathrm{MgF}_{2}$, were added to the flux cored wire, and their effects on the oxygen content of the weld metal were investigated. The investigation showed that the oxygen content of weld metal was not influenced by the type of metallic elements in the fluoride; rather, it was influenced by the stability of the arc during welding. While the wire containing $\mathrm{MgF}_{2}$ showed the most stable arc and the least amount of oxygen in the weld metal, the wire containing $M_{n} F_{3}$ showed the least stable arc and the greatest amount of oxygen. Since the deoxidation of the weld metal was not affected by the deoxidation elements, such as $\mathrm{Ca}$ and $\mathrm{Mg}$, it was possible to predict the oxygen content of the weld metal by the equilibrium Si-Mn deoxidation thermodynamic model.
\end{abstract}

\section{1. 서 론}

최근 선박이나 해양구조물 건조에서 고강도강의 사용이 증대 됨에 따라 용접부 수소균열 발생에 대한 관심이 증대되고 있다. 수소균열은 용접부 중 경화가 쉽게 되는 열영향부에서 주로 발 생되나 최근 탄소량을 억제한 고강도강의 사용에 따라 열영향 부가 아닌 용접금속에서의 발생에도 관심이 증대되고 있다.

수소균열의 억제를 위해서는 전통적으로 예열이나 층간온도 제어, 그리고 후열처리 등이 시행되었다. 하지만 이런 방법들은 시간과 비용 측면에서 효율적이지 못하여 근본적으로 수소함량 이 낮은 저수소형의 용접재료 개발이 요구되어 진다. Matsushita and Liu(2000)은 용접 와이어에 불화물을 첨가하면 아크 분위기 에서 분해한 불소가 수소와 반응하여 불화수소를 만드는데, 이 화합물은 용융금속에 녹지 않아 결과적으로 융융금속의 수소량 을 억제할 수 있다고 하였다. 그들은 불화물 중 $\mathrm{KF}$ 와 $\mathrm{MnF}_{3}$ 등이 $\mathrm{CaF}_{2}$ 보다 $\mathrm{HF}$ 형성이 용이하여 수소억제에 유용하다고 하였다. Du Plessis et al.(2006)은 염기성계 수용접봉을 사용하여 플럭스 중의 $\mathrm{CaF}_{2}$ 와 $\mathrm{NaF}$ 의 상대적인 양을 변경하여 용접금속 확산성수 소량의 변화를 측정한 결과, $\mathrm{CaF}_{2}$ 보다 $\mathrm{NaF}$ 가 수소 저감에 효과적
이라고 하였다. 한편 Bang et al.(2010)은 플럭스 코어드 와이어에 여러 불화물을 첨가하여 용접금속 확산성수소량을 측정한 결과 $\mathrm{CaF}_{2}$ 가 수소량 저하에 가장 효과적이라고 하였다. 이상의 연구에 서 보는 것처럼 용접금속 수소량 저하에 가장 효과적인 불화물의 종류에는 아직 일치된 결과가 없으나 불화물이 용접금속 수소억 제에 효과적 이라는 것에는 일치된 결과를 보이고 있다.

불화물을 첨가한 용접 와이어를 사용하는 경우 불화물의 종 류에 따라 수소량 외에도 용접금속 산소량에도 차이가 날 것으 로 예상된다. 즉 강력한 탈산원소인 $\mathrm{Ca}, \mathrm{Mg}$ 등 알칼리족이나 알칼리토금속족 원소를 함유하는 불화물의 경우 분해된 이들 원소들이 탈산반응을 촉진하여 용접금속 산소량을 감소시킬 것 으로 예상된다. 용접금속 산소량은 용접금속 조직 및 인성에 큰 영향을 미친다고 알려져 있어(Grong and Matlock, 1986; Abson, 1989; Babu et al., 1995) 불화물을 첨가한 용접 와이어를 이용하 는 경우 용접금속 수소량 이외에도 산소량의 변화에도 유의할 필요가 있다. 하지만 아직까지 이러한 연구는 보이지 않아 본 연구에서는 여러 불화물을 첨가한 플럭스 코어드 와이어를 제 조하여 불화물의 종류에 따른 용접금속 산소량의 변화에 대하 여 조사하였다.

Received 13 June 2019, revised 6 November 2019, accepted 23 November 2019

Corresponding author Kook-Soo Bang: +82-51-629-6379, ksbang@pknu.ac.kr ORCID: http://orcid.org/0000-0002-9062-8824

(c) 2019, The Korean Society of Ocean Engineers

This is an open access article distributed under the terms of the creative commons attribution non-commercial license (http://creativecommons.org/licenses/by-nc/3.0) which permits unrestricted non-commercial use, distribution, and reproduction in any medium, provided the original work is properly cited. 


\section{2. 실험방법}

실험에 사용한 용접 와이어는 각각 다른 종류의 불화물을 첨 가하여 목표규격 AWS E81T1-K2에 해당되게끔 제조한 직경 $1.4 \mathrm{~mm}$ 의 플럭스 코어드 와이어이다. 첨가한 불화물은 $\mathrm{CaF}_{2}$, $\mathrm{Na}_{3} \mathrm{AlF}_{6}, \mathrm{~K}_{2} \mathrm{SiF}_{6}, \mathrm{MnF}_{3}, \mathrm{MgF}_{2}$ 5종류로 첨가한 양은 총 플럭스 무 게의 약 $2 \%$ 이다. 불화물 이외 플럭스 성분은 금속분말과 슬래 그 형성제 등으로 모든 와이어에서 동일한 양으로 유지하였다. 저탄소 $\mathrm{Al}$ 탈산강 스트립을 사용하여 플럭스 충진율 $14 \%$ 로 와 이어 를 제조한 후 $350^{\circ} \mathrm{C}$ 에서 건조하여 사용하였다.

용접은 인장강도 $600 \mathrm{MPa}$ 압연강을 사용하여 비드-온-플레이 트(Bead-on-plate)로 하였다. 차폐가스는 $100 \% \mathrm{CO}_{2}$ 가스를 사용하 였으며 용접조건은 $280 \mathrm{~A}-30 \mathrm{~V}-35 \mathrm{~cm} / \mathrm{min}$ 로 유지하였다. 용접 후 용접선에 수직으로 절단하여 용접금속 중앙부에서 화학성분 측 정과 현미경 조직 관찰을 행하였다. 용접금속 산소량에 미치는 용접 아크 안정성의 영향을 확인하기 위하여 용접 중 각 와이 어의 아크 안정성을 측정하였다. 고속 전압전류 측정장치를 이 용하여 용접하는 동안 $5 \mathrm{kHz}$ 주파수로 전류와 전압변화를 측정 하였다. 아크 안정성의 또 다른 지표인 용접 중 스패터 발생량 도 측정하였다. Fig. 1에 나타낸 것과 같은 구리로 만든 스패터 포집장치에 크기가 $400 \times 150 \times 25 \mathrm{~mm}$ 인 압연강판을 위치시킨 후 상기와 동일한 용접 조건으로 비드-온-플레이트 용접하였다. 용 접횟수는 측정에 필요한 충분한 스패터량을 확보하기 위해 와 이어 당 3 회로 하였으며, 용접길이는 비드 하나가 $300 \mathrm{~mm}$ 가 되 도록 하였다. 용접 후 압연강판에 용착된 스패터를 떼어내고 장 치 내에 흩어진 스패터를 자석을 이용해 포집하여 전자저울을 이용해 스패터 전체 무게를 측정하였다. 스패터 발생률은 용착 금속 무게에 대한 스패터 무게로 나타내었다.

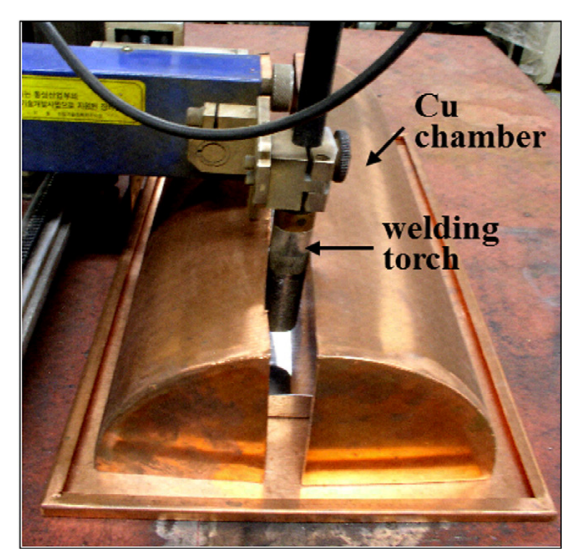

Fig. 1 Apparatus for collecting spatters during welding

\section{3. 실험결과 및 고찰}

사용한 와이어에 따른 각 용접금속의 화학성분을 Table 1에 나타내었다. 산소량은 $\mathrm{MgF}_{2}$ 를 첨가한 와이어가 $0.060 \%$ 로 가장 낮고 $\mathrm{MnF}_{3}$ 를 첨가한 와이어가 $0.078 \%$ 로 가장 높았다. 산소량 이외에 $\mathrm{Si}$ 와 $\mathrm{Mn}$ 량도 차이를 나타내었는데 $\mathrm{MgF}_{2}$ 를 첨가한 와이 어가 각각 $0.31 \%, 1.21 \%$ 로 가장 높은 값을, $\mathrm{MnF}_{3}$ 를 첨가한 와이 어가 각각 $0.19 \%, 0.93 \%$ 로 가장 낮은 값을 나타내었다.

첨가한 불화물 종류에 따라 용접금속에서 산소량이 이러한 차이를 나타내는 원인으로는 각 와이어에서 불화물 성분원소들 의 탈산능력 차이를 먼저 생각할 수 있다. 와이어에 첨가된 불 화물은 아크분위기 중에서 기화 및 분해되어 금속 및 불소원자 를 형성한다. 불소원자는 $\mathrm{H}_{2}$ 혹은 $\mathrm{H}$ 로 존재하는 수소와 결합하 여 $\mathrm{HF}$ 를 형성하나 금속원자는 용융금속에 용해되어 탈산반응 을 한다. Fig. 2에 몇몇 금속원소들의 산화물 형성 경향을 나타 내었다. $\mathrm{Ca}$ 와 $\mathrm{Mg}$ 원소들이 특히 강력한 탈산원소들 임을 알 수 있다. 따라서 $\mathrm{MgF}_{2}$ 를 첨가한 와이어가 낮은 산소량을 나타내는 것은 $\mathrm{Si}$ 와 $\mathrm{Mn}$ 이외에 $\mathrm{Mg}$ 에 의한 강력한 탈산이 한 원인인 것 으로 생각할 수 있다. 하지만 $\mathrm{CaF}_{2}$ 를 첨가한 와이어에서는 $\mathrm{Ca}$ 의 강력한 탈산능력에도 불구하고 낮은 산소량을 보이지 않는다. 더구나 $\mathrm{K}_{2} \mathrm{SiF}_{6}, \mathrm{Na}_{3} \mathrm{AlF}_{6}$ 불화물 첨가 와이어의 경우 분해된 $\mathrm{K}$, $\mathrm{Na}$ 금속원자가 $\mathrm{Ca}$ 에 비하여 탈산능력이 떨어짐에도 불구하고 $\mathrm{CaF}_{2}$ 를 첨가한 와이어와 산소량에 큰 차이를 나타내지 않는다. 이러한 점으로부터 본 실험에서 $\mathrm{Mg}$ 를 제외한 불화물 금속원자

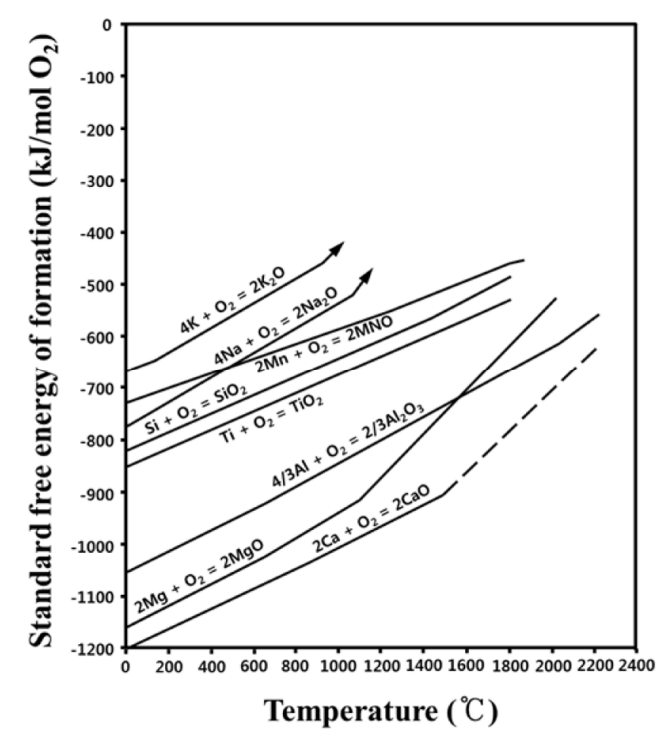

Fig. 2 Standard free energy of formation for selected oxides

Table 1 Chemical composition of weld metals

\begin{tabular}{|c|c|c|c|c|c|c|c|c|c|}
\hline \multirow{2}{*}{ Fluoride } & \multicolumn{9}{|c|}{ Chemical composition [wt $\%]$} \\
\hline & $\mathrm{C}$ & $\mathrm{Si}$ & $\mathrm{Mn}$ & $\mathrm{Al}$ & $\mathrm{Cr}$ & $\mathrm{Ni}$ & $\mathrm{Nb}$ & $\mathrm{Ti}$ & $\mathrm{O}$ \\
\hline $\mathrm{CaF}_{2}$ & 0.030 & 0.26 & 1.16 & 0.0082 & 0.094 & 0.89 & 0.020 & 0.030 & 0.066 \\
\hline $\mathrm{Na}_{3} \mathrm{AlF}_{6}$ & 0.030 & 0.28 & 1.16 & 0.0078 & 0.091 & 1.03 & 0.019 & 0.029 & 0.066 \\
\hline $\mathrm{K}_{2} \mathrm{SiF}_{6}$ & 0.030 & 0.25 & 1.16 & 0.0085 & 0.091 & 0.92 & 0.020 & 0.029 & 0.068 \\
\hline $\mathrm{MnF}_{3}$ & 0.028 & 0.19 & 0.93 & 0.0081 & 0.090 & 1.03 & 0.016 & 0.023 & 0.078 \\
\hline $\mathrm{MgF}_{2}$ & 0.030 & 0.31 & 1.21 & 0.0080 & 0.093 & 0.92 & 0.021 & 0.031 & 0.060 \\
\hline
\end{tabular}





Fig. 3 Comparison of current signals between wires containing different fluorides
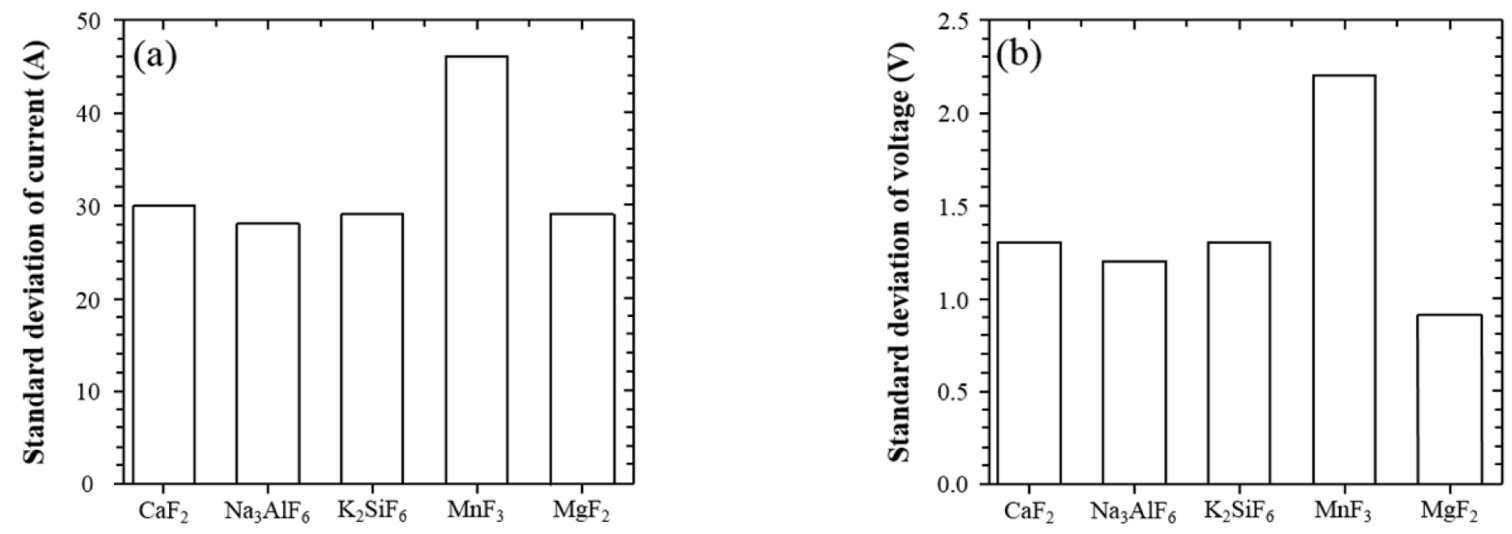

Fig. 4 Comparison of standard deviation of (a) current and (b) voltage between wires containing different fluorides

들의 탈산능력이 용접금속 산소량에 큰 영향을 미치지 않음을 알 수 있다.

일반적으로 용접 중에는 대기로부터 질소, 산소 등 가스성분 이 용융금속으로 용해되는 것을 억제하기 위하여 차폐가스가 사용되며 본 실험에서는 $100 \% \mathrm{CO}_{2}$ 가스를 사용하였다. 하지만 용접 중 아크가 불안정해지면 차폐가 불안정해져 가스성분의 용해가 증대될 것으로 예상된다. 이러한 아크 불안정에 의한 용 접금속 산소량 증대 가능성을 확인하기 위하여 각 와이어의 아 크 안정성과 용접금속 산소량과의 상관성을 조사하였다. 아크 안정성의 한 지표로 앞서 실험방법에서 설명한 것처럼 용접 동 안의 전류와 전압변화를 측정하여 표준편차를 구하였다. Fig. 3 에는 각 와이어를 사용하여 $280 \mathrm{~A}-30 \mathrm{~V}-35 \mathrm{~cm} / \mathrm{min}$ 로 용접하는 동 안 전류변화의 한 예를 나타내었다. 이러한 변화로부터 전류와 전압의 표준편차를 계산하여 Fig. 4에 비교하였다. $\mathrm{MnF}_{3}$ 첨가 와이어의 경우 전류와 전압의 표준편차가 모두 아주 높은 값을 나타내며 $\mathrm{MgF}_{2}$ 첨가 와이어는 전압 표준편차가 낮다. Fig. 5에 는 아크 안정성의 또 다른 지표인 스패터 발생률을 비교한 결 과를 나타내었다. 스패터 발생률은 $\mathrm{MgF}_{2}$ 첨가 와이어가 $1.64 \%$

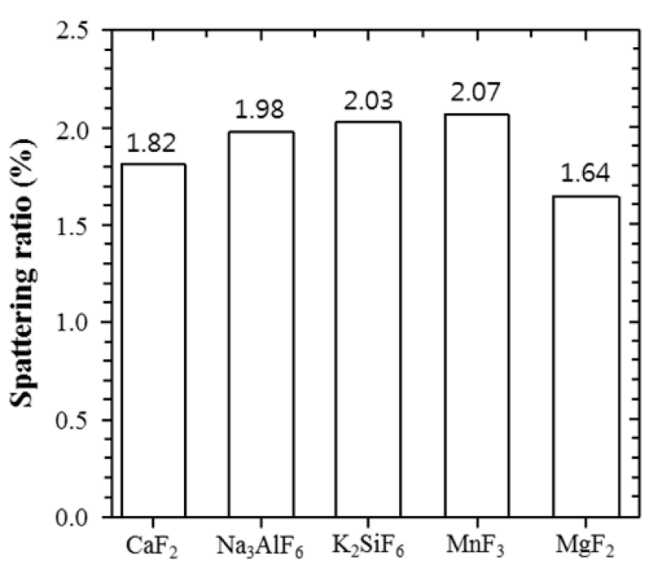

Fig. 5 Comparison of spattering ratio between wires containing different fluorides

로 가장 낮으며 $\mathrm{MnF}_{3}$ 첨가 와이어가 $2.07 \%$ 로 가장 높았다. 이 러한 전류, 전압의 표준편차 그리고 스패터 발생률과 용접금속 산소량의 상관관계를 살펴보면 전압의 편차가 가장 좋은 상관 


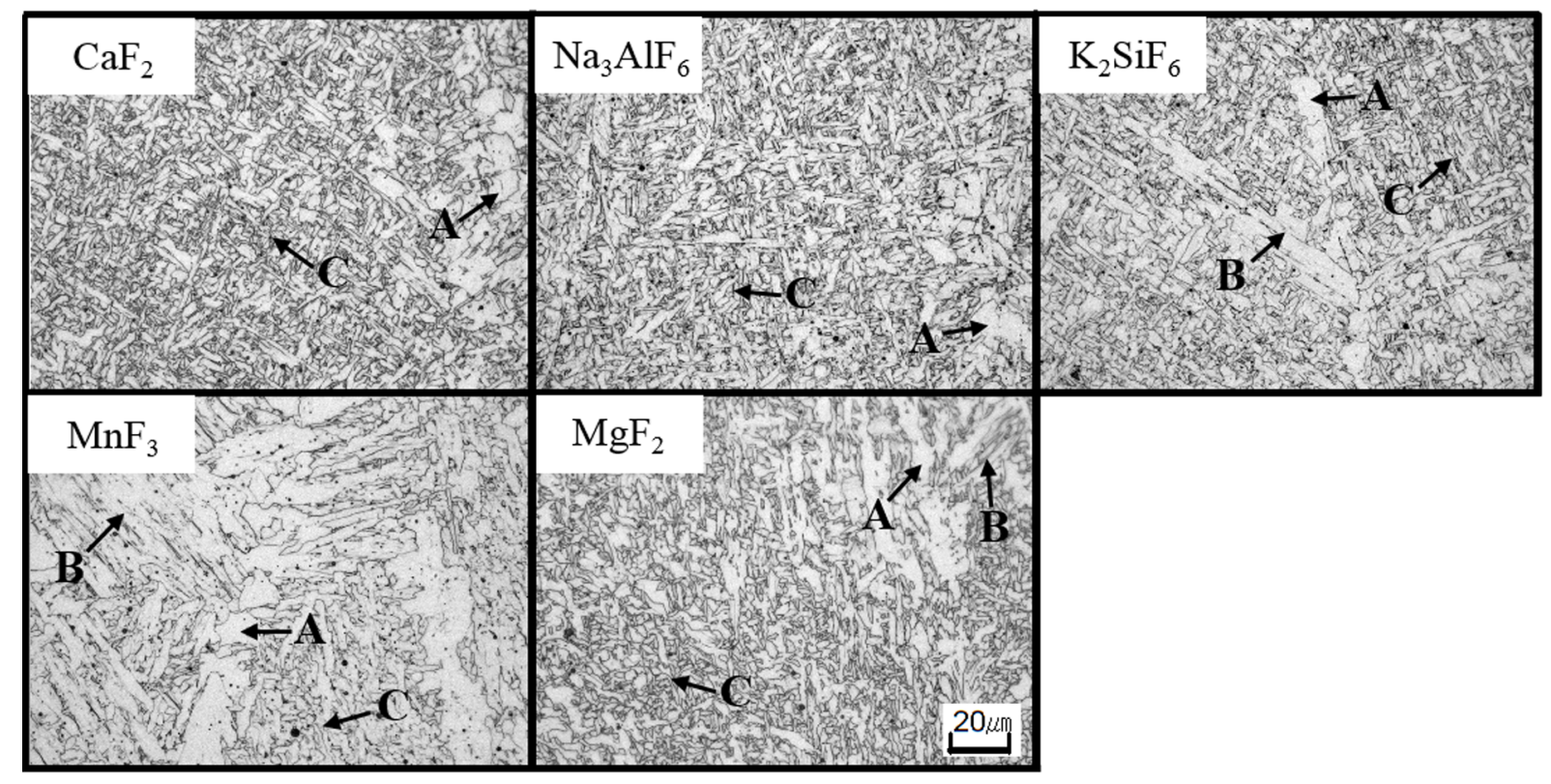

Fig. 6 Comparison of weld metal microstructure between wires containing different fluorides

관계를 나타낸다(수정 결정계수 0.96). 이것은 아크전압이 아크 길이에 비례하기 때문에 전압의 변동에 따라 아크길이가 길어 질 경우가 증가하여 대기로부터 산소 혼입이 더욱 많아지기 때 문으로 생각된다. 따라서 $\mathrm{MgF}_{2}$ 첨가 와이어가 가장 낮은 산소 량을, 그리고 $\mathrm{MnF}_{3}$ 첨가 와이어가 가장 높은 산소량을 나타내 는 원인은 불화물 금속원자들의 탈산능력보다 용접 과정 중 아 크 안정성, 특히 전압변화에 큰 영향을 미치기 때문인 것으로 판단된다.

각 용접금속의 광학현미경 조직관찰 결과를 Fig. 6에 나타내 었다. 모든 용접금속이 입계에서 입계페라이트, 입내에서 침상 페라이트와 페라이트 사이드 플레이트를 나타내나, $\mathrm{MnF}_{3}$ 첨가 와이어의 경우 다른 와이어에 비해 상대적으로 입계페라이트(A 로 표시)와 페라이트 사이드 플레이트(B로 표시)가 많고 침상페 라이트(C로 표시)가 적다. 용접금속 인성이 침상페라이트가 많 을수록 증가함을 고려하면(Ishikawa and Takahashi, 1995; Bala et al., 1993) $\mathrm{MnF}_{3}$ 첨가 와이어의 용접금속은 다른 용접금속에 비 하여 인성이 열악할 것임을 알 수 있다.

동일한 용접조건에서 용접금속 조직은 화학성분에 의하여 결 정되는 경화능에 큰 영향을 받는다. 하지만 산소도 산화물 형성 에 의한 결정립 성장 억제 효과와 침상페라이트 핵생성 효과 등에 의하여 조직 형성에 큰 영향을 미친다(Horii et al., 1995; Hidaka et al., 2008; Okazaki et al., 2009). 따라서 본 실험에서 $\mathrm{MnF}_{3}$ 첨가 와이어 용접금속이 다른 용접금속에 비하여 입계페 라이트와 페라이트 사이드 플레이트가 많고 침상페라이트가 적 은 것은 용접금속 중 $\mathrm{Si}$ 와 $\mathrm{Mn}$ 량의 차이에 의한 경화능의 차이 와 산소량의 차이에 기인하는 것으로 판단된다.

용융금속의 탈산에 불화물 금속원자들이 큰 영향을 미치지 않는다면 탈산은 주로 $\mathrm{Si}$ 와 $\mathrm{Mn}$ 에 의하여 일어날 것이다. 이런 점은 산소량이 많은 $\mathrm{MnF}_{3}$ 와이어 용접금속에서 $\mathrm{Si}$ 와 $\mathrm{Mn}$ 량이 적은 것으로도 확인할 수 있다. 따라서 다음에는 Grong et al.(1986)이 제안한 방법에 따라 본 실험에서 $\mathrm{Si}-\mathrm{Mn}$ 탈산에 의한 용접금속 산소량의 예측을 시도하였다. $\mathrm{Si}-\mathrm{Mn}$ 탈산반응에 의하
여 형성되는 산화물이 망간규산염(Manganese silicate)이라 하면 이 규산염에서 $\mathrm{SiO}_{2}$ 가 미포화되어 $\mathrm{SiO}_{2}$ 의 활동도가 낮을수록 계 속적으로 탈산반응이 일어날 것이다. 따라서 탈산반응의 정도, 즉 용접금속 산소량은 망간규산염 중의 $\mathrm{SiO}_{2}$ 활동도에 의하여 지배된다. 용접금속 중 $\mathrm{Si}$ 와 $\mathrm{O}$ 의 반응에 의한 $\mathrm{SiO}_{2}$ 형성반응과 그때의 평형상수 $\mathrm{K}_{1}$ 은 다음 식 (1), (2)와 같다.

$$
\begin{aligned}
& {[\mathrm{Si}]+2[\mathrm{O}]=\left(\mathrm{SiO}_{2}\right)} \\
& K_{1}=a_{s i o_{2}} /[\% \mathrm{Si}][\% \mathrm{O}]^{2}
\end{aligned}
$$

여기서 $[\% \mathrm{Si}]$ 와 $[\% \mathrm{O}]$ 는 각각 용융금속에서 $\mathrm{SiO}_{2}$ 와 평형하는 $\mathrm{Si}$ 량과 산소량을, $a_{s i o_{2}}$ 는 $\mathrm{SiO}_{2}$ 의 활동도를 나타낸다. 따라서 $a_{s i o_{2}}$ 만 알면 위의 식 (2)를 이용하여 주어진 온도에서 평형산소량을 계산할 수 있다. Walsh and Ramachandran(1963)에 따르면 $\mathrm{Fe}-\mathrm{Mn}-\mathrm{Si}$-O계에 있어서 탈산생성물 중 $a_{s i o_{2}}$ 는 다음 식 (3)과 같 이 주어진다. 따라서 식 (2)와 (3)을 결합하면 용융금속 중 [\% $[\% \mathrm{Si}]$ 와 $[\% \mathrm{Mn}]$ 과 평형하는 산소량, $[\% \mathrm{O}]$ 를 나타내는 식 (4)를 얻을 수 있다.

$$
\begin{aligned}
& a_{s i o_{2}}=K_{2}[\% \mathrm{Mn}]\left[\% \mathrm{Si}^{-0.5}\right. \\
& {[\% \mathrm{O}]=K_{3}[\% \mathrm{Si}][\% \mathrm{Mn}]^{-0.25}}
\end{aligned}
$$

여기서 식 (4)의 평형상수 $K_{3}$ 는 $\left(K_{2} / K_{1}\right)^{0.5}$ 로 아래의 식 (5)와 같 이 주어진다.

$$
\log K_{3}=-15,518 / \mathrm{T}+6.01
$$

Fig. 7에 본 실험에서 용접금속 중 산소량의 변화를 ([Si\%][Mn\%] $)^{-0.25}$ 에 따라 나타내었다. 그림에서 실선은 용융금속의 온도를 $1845^{\circ} \mathrm{C}$ 로 하여 계산한 경우로 측정한 $\mathrm{Si}, \mathrm{Mn}$ 및 산소량과 잘 대응하고 


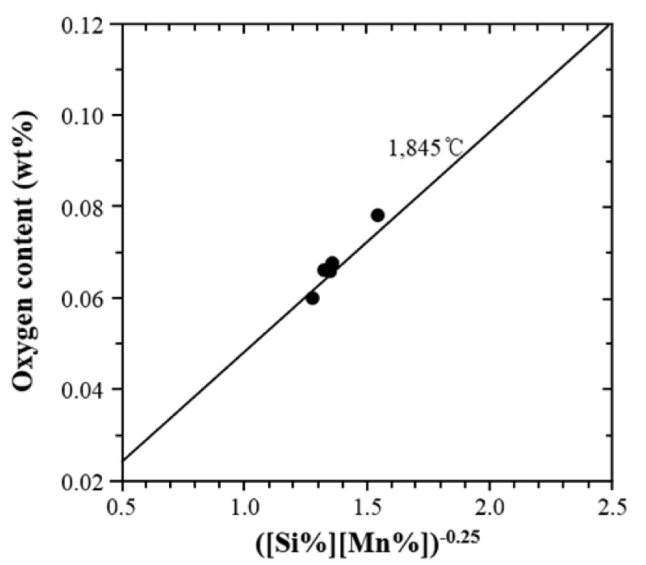

Fig. 7 Relationship between weld metal oxygen content and deoxidation parameter $([\mathrm{Si} \%][\mathrm{Mn} \%])^{-0.25}$

있다. 즉 불화물 첨가 와이어를 사용하여 용접한 본 실험에서 용접 금속의 산소량은 반응온도가 $1845^{\circ} \mathrm{C}$ 인 $\mathrm{Si}-\mathrm{Mn}$ 탈산을 가정한 평형 열역학을 가정하여 예측 가능함을 알 수 있다.

\section{4. 결 론}

$\mathrm{CaF}_{2}$ 등 여러 불화물을 첨가한 플럭스 코어드 와이어를 제조 한 후 $100 \% \mathrm{CO}_{2}$ 용접하여 불화물 종류에 따른 용접금속 산소 량의 변화를 조사한 결과 다음과 같은 결론을 얻었다.

(1) 용접금속의 산소량은 불화물 금속원자들의 탈산능력보다 용접 과정 중 아크 안정성에 더 큰 영향을 받는 것으로 확인할 수 있었다.

(2) $\mathrm{MgF}_{2}$ 첨가 와이어가 가장 안정한 아크를 그리고 $\mathrm{MnF}_{3}$ 첨 가 와이어가 가장 불안정한 아크를 나타내어, 그에 따라 용접금 속에서 각각 가장 낮은 산소량과 높은 산소량을 얻었다.

(3) 용융금속의 탈산, 즉 용접금속의 산소량은 첨가한 불화물 의 종류와 상관없이 반응온도가 $1845^{\circ} \mathrm{C}$ 인 Si-Mn 탈산을 가정한 평형열역학에 의하여 예측 가능함을 확인할 수 있었다.

\section{후기}

이 논문은 부경대학교 자율창의학술연구비(2019년)에 의하여 연구되었음.

\section{References}

Abson, D., 1989. Non-metallic Inclusions in Ferritic Steel Weld Metals. Welding in the World, 27(3/4), 76-101.

Babu, S.S., David, S.A., Vitek, J.M., Mundra, K., DebRoy, T., 1995.
Development of Macro- and Microstructures of Carbon-Manganese Low Alloy Steel Welds: Inclusion Formation. Materials Science and Technology, 11(2), 186-199. https://doi.org/10.1179/mst.1995. 11.2.186

Bala, S.R., Malik, L., Braid, J.E.M., 1993. Evaluation of FCAW Consumables for Offshore and Arctic Structure Fabrication. Journal of Offshore Mechanics and Arctic Engineering, 115(2), 76-82. https://doi.org/10.1115/1.2920094

Bang, K.-S., Jung, H.-C., Han, I.W., 2010. Comparison of the Effects of Fluorides in Rutile-Type Flux Cored Wire. Metals and Materials International, 16(3), 489-494. https://doi.org/10.1007/s12540-0100622-6

Du Plessis, J., Du Toit, M., Pistorius, P., 2006. Reducing the Diffusible Hydrogen Content of Shielded Metal Arc Welds by Menas of Fluoride and Calcite Flux Additions. IIW Doc., II-1590-06.

Grong, O., Matlock, D.K., 1986. Microstructural Development in Mild and Low-Alloy Steel Weld Metals. International Metals Reviews, 31(1), 27-48. https://doi.org/10.1179/imtr.1986.31.1.27

Grong, O, Siewert, T., Martins, G., Olson, D., 1986. A Model for the Silicon-Manganese Deoxidation of Steel Weld Metal. Metallurgical Transactions A, 17(10), 1797-1807. https://doi.org/10. 1007/BF02817277

Hidaka, T., Suenaga, K., Okazaki, Y., Ishida, H., 2008. Influence of Oxides on Microstructure and Notch Toughness of Weld Metal with Flux Cored Wires for High Strength Steel. IIW Doc., II-1710-09.

Horii, Y., Ichikawa, K., Ohkita, S., Funaki, S., Yurioka, N., 1995. Chemical Composition and Crystal Structure of Oxide Inclusions Promoting Acicular Ferrite Transformation in Low Alloy Submerged Arc Weld Metal. Quarterly Journal of Japan Welding Society, 13(4), 500-507. https://doi.org/10.2207/qjjws.13.500

Ishikawa, F., Takahashi, T., 1995. The Formation of Intragranular Ferrite Plates in Medium-carbon Steels for Hot-forging and Its Effect on the Toughnes. ISIJ International, 35(9), 1128-1133. https:// doi.org/10.2355/isijinternational.35.1128

Matsushita, M., Liu, S., 2000. Hydrogen Control in Steel Weld Metal by Means of Fluoride Additions in Welding Flux. Welding Journal, 79(10), 295s-303s.

Okazaki, Y., Ishida, H., Suenaga, K., Hidaka, T., 2009. Influence of Oxide Inclusion Compositions on Microstructure and Toughness of Weld Metal for High Strength Steel. Quarterly Journal of Japan Welding Society, 27(2), 131-138. https://doi.org/10.2207/qijws. 27.131

Walsh, R., Ramachandran, S., 1963. Equilibrium in the Fe-Mn-Si-O System. Transactions of Metallurgical Society of AIME, 227(6), 560-562. 